\title{
Genetic diversity and structure of Fusarium oxysporum f.sp. lentis isolates from Iran,
}

\section{Syria and Algeria}

Hamid R. Pouralibaba ${ }^{1,2}$, Zlatko Satovic ${ }^{3,4}, \mathrm{M}^{\mathrm{a}}{\text { José } \operatorname{Cobos}^{1} \text {, Diego Rubiales }}^{1}$, Sara Fondevilla $^{1}$

${ }^{1}$ Institute for Sustainable Agriculture, CSIC, Avda. Menéndez Pidal s/n, 14004 Córdoba, Spain

${ }^{2}$ Dryland Agricultural Research Institute; Agricultural Research, Education and Extension Organization (AREEO), Maragheh, Iran

${ }^{3}$ University of Zagreb, Faculty of Agriculture, Department of Seed Science and Technology, Svetošimunska 25, 10000 Zagreb, Croatia

${ }^{4}$ Centre of Excellence for Biodiversity and Molecular Plant Breeding (CroP-BioDiv), Svetošimunska 25, 10000 Zagreb, Croatia

\section{Abstract}

Lentil is an important cool season food legume. Vascular wilt incited by Fusarium oxysporum f.sp. lentis (FOL) is the most important disease of lentil worldwide. Knowledge of pathogen genetic structure is crucial to develop effective control strategies. In this study, the genetic structure of a collection of FOL isolates from Iran, Syria and Algeria was analysed using SSR markers. Eight of them were developed in this study and constitute a valuable resource for future molecular studies in FOL. Our results showed that there is a high molecular variation within regions, with isolates from North West Iran showing the highest gene diversity. Variation among regions also exists, with Iranian populations differing significantly from non-Iranian ones, having some private alleles. The clustering of isolates was well in agreement in both distance-based and model-based approaches suggesting the presence of seven ancestral FOL lineages, being three present exclusively in Iran while the others were distributed across all the regions. These results suggest that Iran could be a regional center of origin for FOL.

Keywords: Lentil (Lens culinaris), Fusarium oxysporum f.sp. lentis, population structure, pathotype, SSR

\section{Introduction}

Lentil (Lens culinaris Medikus subsp. culinaris) is one of the most important cool season food legumes in India, northern Africa, western Asia, southern Europe, North and South America, and Australia (Erskine and Bayaa 1996). World production of lentil is estimated at 4.95 million tons from an estimated 4.34 million ha with an average yield of $1140 \mathrm{Kg} / \mathrm{ha}$ (FAOSTAT 2013 http://faostat.fao.org/faostat/collections). Their seeds are a rich source of 
proteins, minerals and vitamins for human nutrition, and the straw is used for animal feeding. As for most crops, a number of biotic and abiotic stresses decrease lentil yield (Chen et al. 2009). Of them, vascular wilt, caused by Fusarium oxysporum f.sp. lentis Gordon, from now on referred as FOL, is the most important disease of lentil worldwide (Bayaa et al. 1998; Khare 1981). The pathogen is able to attack the plant in almost every stage of the growth and can survive for several seasons in the soil without the host (Erskine and Bayaa 1996).

The most effective, economical and environmentally friendly method to control the disease is the use of resistant cultivars (Bayaa et al.1995; Kraft et al. 2000). Health or disease is the result of a battle between plants and their pathogens, the final outcome depending on the interaction between the genetic factors of both parts of the interaction. Therefore, knowledge of the genetic structure of pathogens populations is relevant for planning managing strategies to control the diseases and enhance resistance durability. Thus, the level of genetic diversity and the capacity of a pathogen to evolve and create more aggressive isolates determine the potential of pathogens to overcome plant resistance genes.

Molecular markers offer a powerful method for revealing and identifying population structure of a pathogen and have been extensively used to study genetic diversity in different pathogens including different formae speciales and races of $F$. oxysporum (Grajal-Martin et al. 1993; Bentley et al. 1994; Manulis et al. 1994; O'Donnell et al. 1998; Baysal et al. 2009; Lievenes et al. 2009).

Genetic structure analysis and variability of FOL populations have been tackled using different methods such as vegetative compatibility groups, IGS (intergenic spacer), ISSRs (inter-simple sequence repeat), SSRs (simple sequence repeat), RAPDs (random amplified polymorphic DNA), rDNA (ribosomal DNA) and AFLPs (amplified fragment length polymorphism) (Belabid and Fortes 2002; Belabid et al. 2004; Taheri et al. 2010; Datta et al. 2011; Mohammadi et al. 2012; Al-Husien et al 2017; Nourollahi1 \& Madahjalali 2017). Among molecular markers, SSRs have a number of advantages such as high level of polymorphisms, locus specificity, co-dominance, reproducibility, and random distribution throughout the genome (Saghai Maroof et al. 1995). However, only a few SSR are available for FOL. Thus, the only SSRs used so far for this species are SSRs developed by Bogale et al. (2005) for the $F$. oxysporum complex.

Previous studies on FOL population genetics have studied isolates from a specific geographic region such as India, Iran, Syria or Algeria (Belabid et al. 2004; Taheri et al. 2010; Datta et al. 2011; Mohammadi et al. 2011; Al-Husien et al 2017; Nourollahi1 \& Madahjalali 2017). In addition, some of these studies analysed the relationship between genetic structure 
and isolates aggressiveness. However, as FOL pathoypes have only recently been identified (Pouralibaba et al. 2016), nothing is known about the possible relationship between genetic structure and pathoypes.

The aim of this study was to use SSR markers to study the genetic structure of FOL populations covering a wide geographical region (Iran, Algeria and Syria), and to study whether there is any relation between this genetic structure and pathotypes. In addition, in order to perform a more accurate analysis, covering a higher genomic area, some new SSRs were developed for FOL.

\section{Materials and Methods}

\section{Fungal material}

Forty seven FOL isolates and one F. oxysporum f. sp. pisi (FOP) isolate were used in this study (Table 1). FOL isolates originated from Iran (isolates from North East of Iran kindly provided by Dr. N. Mohammadi, Tarbyat Modarres University,Tehran), Syria (kindly provided by Dr. S. Ahmed, ICARDA, Syria) and Algeria (kindly provided by Dr. L. Belabid, University of Mascara, Algeria). The FOP isolate originated from Pullman, USA and was kindly provided by Dr. W. Chen. Isolates were first obtained from naturally yellowed/wilted lentil plants and subsequently purified to obtain mono-conidial isolates, which were stored at $80^{\circ} \mathrm{C}$ as micro conidial suspensions in $150 \mathrm{ml}$ vials containing $70 \mathrm{ml}$ spore suspension: $30 \mathrm{ml}$ sterile $98 \%$ glycerol. Isolates were characterized as $F$. oxysporum on Carnation Leaf Agar (CLA), using the key proposed by Nelson et al. (1983) and kindly confirmed by Prof. A. Trapero-Casas, University of Córdoba, Spain. Pathogenicity and characterization of isolates as FOL was tested by inoculating the lentil susceptible cultivar "Ardebil Local" with the isolates. To avoid any possible loss of virulence due to the effect of long storage or consecutive growing in medium, all isolates were inoculated on and re-isolated from the susceptible lentil cultivar "Ardebil Local" before performing the studies.

\section{DNA extraction and SSR analysis}

DNA was extracted from mycelium obtained from the fungus growing in PDB (Potato Dextrose Broth) liquid medium. Fungal isolates were grown in a $250 \mathrm{ml}$ flasks containing 100 $\mathrm{ml} \mathrm{PDB}$ (200gr potato: 20gr glucose: $1 \mathrm{~L}$ distilled water) at 28 to $30^{\circ} \mathrm{C}$ for 3 to 4 days on a shaker in darkness. To obtain mycelia samples, the culture was filtered through four layers of 
sterile cheesecloth, washed in distilled sterile water, dried with filter paper and stored at $80^{\circ} \mathrm{C}$. DNA was isolated using CTAB method (Lassner et al. 1989), with the modifications described by Torres et al. (1993). Nine SSR developed by Bogale et al. (2005) for the $F$. oxysporum complex (MB2, MB5, MB9, MB10, MB11, MB13, MB14, MB17, MB18) and 11 developed by Vogelsang et al. (2011) for Fusarium poae (FP01, FP03, FP05, FP06, FP06, FP07, FP08, FP09, FP10, FP11, FP12, FP14) were surveyed in the FOL populations. In addition, we designed new SSRs primers. In the absence of available sequences for FOL, we made use of the $F$. oxysporum f. sp. pisi HDV247 whole genome shotgun sequencing project (GenBank accession AGBI00000000.1). Using these F. oxysporum f. sp. pisi sequences as templates, twenty-three SSR were identified and primers designed using BatchPrimer3 software (You et al., 2008). Primer design parameters were: length range $=18$ to 23 nucleotides, with 21 as optimum, optimum annealing temperature $55^{\circ} \mathrm{C}$ and $\mathrm{GC}$ content 40 $60 \%$.

For SSRs earlier described by Bogale et al. (2005) and Vogelsang et al. (2011) PCR reaction mix and amplification conditions initially used were as reported by the authors. In the case of absence of amplification, different annealing temperatures and $\mathrm{MgCl}_{2}$ concentrations were tested. For the SSRs newly developed in this study, amplification conditions were as reported by Bogale et al. (2005) and annealing temperatures and $\mathrm{MgCl}_{2}$ concentration were optimized (Table 2). Amplification products were first subjected to electrophoresis performed in a 2\% agarose with Tris-borate EDTA Buffer gels for $3 \mathrm{~h}$ at $90 \mathrm{~V}$. Gel green-stained gels were visualized on an ultraviolet light transilluminator and photographed. Only SSRs showing a clear unique band were selected for fragment analysis. For fragment analysis, SSRs were amplified in PCR reactions in a total volume of $15 \mu$, containing: $50 \mathrm{ng}$ of genomic DNA; $10 \mathrm{x} \mathrm{NH}_{4}$ reaction buffer $\left(670 \mathrm{mM}\right.$ Tris- $\mathrm{HCl}\left(\mathrm{pH} 8.8\right.$ at $\left.25^{\circ} \mathrm{C}\right), 160 \mathrm{mM}\left(\mathrm{NH}_{4}\right)_{2} \mathrm{SO}_{4}, 100 \mathrm{mM}$ $\mathrm{KCl}, 10,0.1 \%$ stabilizer); $160 \mu \mathrm{M}$ of dNTPs; 1.5 or $2.5 \mathrm{mM}$ of $\mathrm{MgCl}_{2}$ depending on the primer (Table 2); $0.2 \mu \mathrm{M}$ of primers and 0.6U BIOTAQ DNA polymerase (Bioline). Forward primers were labeled with fluorophores 6FAM or HEX (Sigma-Genosys Ltd.) at the 5' ends. The thermal profile consisted of an initial denaturation at $94^{\circ} \mathrm{C}$ for $5 \mathrm{~min}$ followed by 35 cycles of $94^{\circ} \mathrm{C}$ for $30 \mathrm{~s}$, annealing temperature for 30 s (Table 2) and $72^{\circ} \mathrm{C}$ for 30 s, concluding with a final extension step at $72^{\circ} \mathrm{C}$ for $10 \mathrm{~min}$. Amplification products were separated in an automated capillary sequencer (ABI 3130 Genetic Analyzer, Applied Biosystems /HITACHI) at the Genomics Unit of the Central Service of Research Support at the University of Córdoba (Spain). The size of the amplified bands were calculated based on an internal standard DNA 
(400HD-ROX, Applied Biosystems) with GeneScan software (v 3.x Applied Biosystems) and the results analysed using the Genotyper software (v 3.7, Applied Biosystems).

\section{Data analysis}

Total number of alleles and expected heterozygosity $\left(H_{E}\right)$ of each of the 12 microsatellite markers in a set of 47 Fusarium oxysporum $\mathrm{f}$. sp. lentis isolates as well as the average number of markers $\left(N_{a v}\right)$, the number of private markers $\left(N_{p r}\right)$ and unbiased expected heterozygosity $\left(H_{E}\right)$ within each of four regions [P1 Algeria, P2 Syria, P3 North West (NW) Iran and P4 North East (NE) Iran] were calculated using ARLEQUIN ver. 3.0 (Excoffier et al., 2005). Allelic richness $\left(N_{a r}\right)$ and private allelic richness $\left(N_{\text {par }}\right)$ within each population were estimated after controlling for differences in sample size using the rarefaction method (Kalinowski, 2004) implemented in the program HP-Rare (Kalinowski, 2005).

For each SSR, the sequences located between the forward and reverse primers in GenBank accession AGBI00000000.1 were blasted (discontiguous megablast) against the whole genome sequence of Fusarium oxysporum f. sp. lycopersici 4287 (Sequence ID: NC_030994.1). Linkage disequilibrium (LD) between all pairs of loci was calculated within each population using GENEPOP ver. 4.7.0 (Rousset, 2008). The sequential Bonferroni adjustments were applied to correct for the effect of multiple tests using SAS release 8.02 (SAS Institute 2004).

Genetic distances between pairs of samples (47 FOL and 1 FOP isolate) were calculated based on six microsatellite loci using the proportion-of-shared-alleles distances ( $D_{p s a}$; Bowcock et al. 1994) as implemented in MICROSAT (Minch et al. 1997). Cluster analysis was performed using the Fitch-Margoliash method in the PHYLIP ver. 3.6b software (Felsenstein 2004). The reliability of the tree topology was assessed via bootstrapping (Felsenstein 1985) over 1,000 replicates generated by MICROSAT and subsequently used in FITCH and CONSENSE programs in PHYLIP. The tree was rooted using FOP isolate as an outgroup.

The analysis of molecular variance (AMOVA; Excoffier et al. 1992) was carried out using ARLEQUIN. AMOVA was used to partition the total microsatellite diversity among and within regions. The variance components were tested statistically by non-parametric randomisation tests using 10,000 permutations. Pairwise population comparisons examined with AMOVA resulted in values of $\phi_{S T}$ that are equivalent to the proportion of the total variance that is partitioned between two regions. 
A model-based clustering method was applied on multilocus microsatellite data to define the number of clusters in the dataset using the software STRUCTURE ver. 2.3.4 (Pritchard et al., 2000). Thirty runs per each $K$ were done by setting the number of clusters $(K)$ from 1 to 11 on the Isabella computer cluster at the University of Zagreb, University Computing Centre (SRCE). Each run consisted of a burn-in period of 200,000 steps followed by $10^{6}$ Monte Carlo Markov Chain replicates assuming admixture model. The choice of the most likely number of clusters $(K)$ was carried out by calculating an ad hoc statistic $\Delta K$ based on the rate of change in the log probability of data between successive $K$ values, as described by Evanno et al. (2005). The program STRUCTURE HARVESTER v0.6.92 was used to process the STRUCTURE results files (Earl Dent and van Holdt 2012). Runs were clustered and averaged using CLUMPAK (Kopelman et al. 2015).

The likelihood-ratio chi-square test in SAS (SAS Institute 2004) was used to test for dependence between cluster membership and pathotype of the isolates. The strength of association was assessed by calculating Cramér's V, the measure that reaches the maximum value of 1 when the two variables (i.e. classification criteria) are equal to each other. The pathotypes represented by less than five isolates ( 4 and 6) were excluded from the analysis.

\section{Results}

\section{SSR analysis}

Twelve SSRs, four from Bogale et al. (2005) and eight new SSRs developed in this study, were successfully amplified and yielded clear reproducible bands in the FOL populations analysed (Table 2). In some isolates, for some SSRs, fragment analysis identified more than one band. In this case only those clear bands, with a reproducible pattern in the population and of the expected size were selected. None of the SSRs developed by Vogelsang et al. (2011) amplified in our samples.

The average number of alleles per SSR was five, being MB2 the most polymorphic, showing ten different alleles, and SSR14 and SSR17 the least polymorphic, both showing only two alleles. Expected heterozygosity ranged from 0.313 (SSR14) to 0.867 (MB2) being 0.657 as average (Table 2).

Blasting of the expected sequence amplified by the SSRs against Fusarium oxysporum f. sp. lycopersici genome identified sequences highly similar (from 96 to $99 \%$ identity) in $F$. oxysporum f. sp. lycopersici chromosomes 1, 4, 5, 7, 8 and 9 (Table 2). Several of the markers analysed were located in the same chromosome. Considering the isolates from the largest 
population (NW Iran), the significant linkage disequilibrium $(P<0.05)$ was observed between loci MB11 and MB18 $(P=0.004)$ both located in the chromosome 4. The same was true for the loci SSR14 and SSR15 $(P=0.017)$ in the chromosome 7 and between loci SSR 21 and SSR23 $(P=0.000)$ in the chromosome 8 . Three out of six pairwise tests for linkage disequilibrium between four loci located in the chromosome 5 (SSR6, SSR8, SSR17, SSR18) were significant including the test between the most distant loci (SSR17 and SSR6; $P=$ 0.002). Therefore, in order to avoid linkage disequilibrium effect, only one SSR per chromosome was selected (Table 2) for further analyses concerning genetic relationships and population structure.

\section{FOL population genetic characterization}

Regarding FOL populations, four regions were initially considered, Algeria, Syria, North West Iran (NW Iran) and North East Iran (NE Iran). NW Iran showed the highest allelic richness $\left(N_{a r}\right)$ as well as the highest unbiased expected heterozygosity $\left(H_{E}\right)$ (Table 3.). In addition, the private alleles were found exclusively in Iranian populations although it could be the effect of the sample size as shown by the values of privated allelic richness.

The genetic distance between pairs of FOL isolates based on the proportion-of-sharedalleles distance measure ranged from $D_{p s a}=0.000$ (76 genetically identical pairs of isolates) to $D_{p s a}=1.000$ (256 pairs of isolates having no alleles in common) with the average of $D_{p s a}$ a $=0.709$.

AMOVA showed that the observed genotypic variation in the FOL isolate collection was mainly due to the variation present within regions (accounting for $86.55 \%$ of the observed variation), but that variation among regions also exist and these differences were statistically significant (Table 4). Pairwise $\phi_{S T}$ values showed that Algeria and Syria isolates differed significantly from Iranian isolates (Table 5).

To further verify these results, an additional AMOVA was carried out to check whether the observed genotypic variation was caused by the variation present among Iranian vs non Iranian regions. This AMOVA showed that considering Iranian regions as one group and non Iranian regions as another group, differences within groups were not significant, but the groups differed significantly from each other (Table 6).

Population structure analysis performed by using STRUCTURE software also reinforced these results. For choosing the most likely number of clusters $(K)$ we used ad hoc statistic $\Delta K$ based on the rate of change in the log probability of data between successive $K$ values, as described by Evanno et al. (2005). The best results were obtained at $K=7$ ( $\Delta K$ 
$=40.68)$ followed by those at $\mathrm{K}=2(\Delta K=23.35)$ (Fig. 1). At $\mathrm{K}=2$ the cluster A included the FOP isolate along with 21 isolates originating exclusively from Iran (NW and NE), while 26 isolates from all the regions were assigned to the cluster B (Fig. 2). At $K=7$, cluster A was divided in three clusters (A1, A2 and A3), being the FOP isolate located in cluster A1. Clusters B was divided in four clusters. Clusters B1 and B2 included isolates only from Syria and North West Iran, while clusters B3 and B4 included isolates from all regions (Fig. 2). The clusters identified by STRUCTURE were in agreement with the distance-base analysis (i.e. Fitch-Margoliash tree) results (Fig. 2).

The association between cluster membership and the pathotype of the isolates was not significant neither at $\mathrm{K}=2\left(\chi^{2}=0.55 ; \mathrm{df}=4 ; P=0.986\right.$; Cramér's $\left.\mathrm{V}=0.11\right)$ nor at $\mathrm{K}=7\left(\chi^{2}\right.$ $=23.37 ; \mathrm{df}=24 ; P=0.498 ;$ Cramér's $\mathrm{V}=0.32$ ).

\section{Discussion}

Understanding the genetic structure of plant pathogen populations is a strategy that estimates the pathogen evolutionary potential and allows management strategies to be chosen, with the aim of enhancing the durability of resistant varieties and determines cultivar deployment strategies (McDonald \& Linde 2002). Simple sequence repeats (SSRs) provide a powerful tool for taxonomic and population genetic studies (Bogale et al. 2005). They are locus specific, highly reproducible and can be scored in a high-throughput way. However, up to now only a few SSRs were available for FOL. In fact, the only SSRs used so far for this pathogen were the nine SSRs markers reported by Bogale et al. (2005) for the Fusarium oxysporum complex. In the present study we have developed eight new SSR markers that were successfully amplified in FOL, increasing markedly the molecular markers available for this specie.

The FOL collection studied included isolates from Iran, Syria and Algeria, being, so far, the study analysing the genetic diversity of FOL covering the widest geographical region. Our results showed that there is a high molecular variation within regions, being NW Iran the region that showed the highest genetic diversity. Previous studies have also concluded that most of the variance of genetic variation occurred within populations (Al-Husien et al 2017; Nourollahi1 \& Madahjalali 2017). This high diversity within populations can be due to a high rate of mutation or presence or transposable elements in the genome as reported by Ma et al. (2010), and could explain the existence of different pathotypes in FOL.

Despite this high molecular variation within isolates from the same region, our studies also show that there are significant differences between regions. Thus, Iranian populations 
differed significantly from non Iranian populations and private alleles were identified exclusively in populations collected in Iran. In addition, cluster A, identified by STRUCTURE software at $\mathrm{K}=2$ was only present in Iran.

No sexual stage is yet known for $F$. oxysporum and populations are expected to be formed by a mixture of clonal lineages. The spatial distribution of these clonal lineages is caused by the dispersion of the asexual propagules. STRUCTURE software predicted that the FOL isolates studied belonged to seven different lineages. Excepting isolate S46, al isolates showed a high value of $\mathrm{Q}$ (proportion of membership), suggesting the absence or low level of interbreeding between lineages.

Our results are in agreement with previous studies. Thus, Al-Husien et al. (2017) concluded that the FOL isolates from Syria they studied could be divided in three populations. In our study, for $K=7$, the isolates from Syria analysed were also distributed in three different clusters. Similarly, Belabid et al. (2004), reported that FOL isolates from Algeria could be clustered in two main groups, and the isolated from this region we included were also located in two clusters. Nourollahil \& Madahjalali (2017) concluded that isolates from Iran could be genetically clustered in three main genetic groups. These groups could correspond to the three main clusters (A1, A2 and A3) identified in our study including only isolates from Iran, although some isolated from Iran were also present in other clusters in our study.

Previous studies concluded the presence from two to three lineages in FOL (Belabid et al. 2004; Datta et al. 2011; Al-Husien et al 2017; Nourollahi1 \& Madahjalali 2017). While previous studies analyzing FOL genetic structure were limited to isolates from a reduced geographical region, our study is the first including isolates from three different countries. This allowed us to identify a higher number of lineages in FOL than previously reported (up to seven) and to obtain information about the evolution and possible spread of FOL across countries. However, the presence of a peak of $\ln \mathrm{P}(\mathrm{X} \mid \mathrm{K})$ at $\mathrm{K}=2$ suggest that these 7 lineages could derive from two ancestral lineages.

Older fungal populations have more alleles than younger ones as there have been more generations for mutation to occur and then for genetic drift to increase these alleles to a detectable frequency (McDonal and Linde 2002). In our study Iran was the region showing the highest FOL genetic diversity and one of the predicted ancestral clonal lineages (A), closely related to FOP was only present in this region. These results suggest that Iran could be a regional center of origin for FOL and that ancestor A could be the oldest clonal lineage. 
Later on, mutations from this ancestor A could result in the appearance of ancestor B, that was later on dispersed to other geographical regions (Syria and Algeria).

No clear relationship could be established between genetic similarity (i.e. cluster membership) and pathotype of the isolates. Previous studies also concluded that phylogenetic similarity cannot be related to virulence group membership, being different $F$. oxysporum formae speciales spread out across the different lineages (Baayen et al. 2000; Bao et al. 2002; Bogale et al. 2006). This result is not surprising, as differences in virulence could be caused by a single mutation in isolates coming from any ancestral lineage and selected under a certain selection pressure.

\section{Acknowledgments}

This research was carried out based on PhD educational mission No. 3972/200-28/1/1389 of first author from Agricultural Research, Education and Extension Organization (AREEO) of Iran and financially supported by Project AGL2014-52871-R co-financed by FEDER. The authors wish to tanks Professor B. Bayaa, University of Aleppo, Syria, for helping to obtain Algerian isolates of FOL.

\section{Compliance with Ethical Standards}

Conflict of Interest: The authors declare that they have no conflict of interest. All authors have revised the manuscript and approved its submission.

\section{References}

Al-Husien ,N.H., Hamwieh, A., Ahmed, S., \& Bayaa, B. (2017). Genetic diversity of Fusarium oxysporum f.sp. lentis population affecting lentil in Syria. Journal of Phytopathology, 165, 306-312.

Bao, J.R., Fravel, D.R., O'Neill, N.R., Lazarovits, G. \& van Berkum, P. (2002). Genetic analysis of pathogenic and non-pathogenic Fusarium oxysporum from tomato plants. Canadian Journal of Botany, 80, 271-279.

Bayaa, B., Erskine, W., \& Hamdi, A. (1995). Evaluation of a wild lentil collection for resistance to vascular wilt. Genetic Resources and Crop Evolution,42, 231-235.

Bayaa, B., Kumari, S.G., Akkaya, A. \& Erskine, W. (1998). Survey of major biotic stresses of lentil in South-East Antalia, Turkey. Phytopathologia Mediterranea 37, 88-95.

Baayen, R.P., O'Donnell, K., Bonants, P.J.M., Cigelnik, E., Kroon, L.P.N.M., Roebroeck, E.J.A. \& Waalwijk, C. (2000). Gene genealogies and AFLP analysis in the Fusarium oxysporum complex identify monophyletic and non-monophyletic formae speciales causing wilt and rot diseases. Phytopathology 90, 891-900. 
Baysal, Ö., Siragusa, M., Ikten, H., Polat, E., Gümrükcü, E., Yigit, F., Carimi, F. \& Teixeria da Silva, J.A. (2009). Fusarium oxysporum f. sp. lycopersici races and their genetic discrimination by molecular markers in West Mediterranean region of Turkey. Physiological and Molecular Plant Patholgy, 74, 68-75.

Belabid, L., \& Fortas, Z. (2002). Virulence and vegetative compatibility of Algerian isolates of Fusarium oxysporum f. sp. lentis. Phytopathologia Mediterranea, 41, 179-187.

Belabid, L., Baum, M., Fortas, Z., Bouznad, Z., \& Eujayl, I. (2004). Pathogenic and genetic characterization of Algerian isolates of Fusarium oxysporum f. sp. lentis by RAPD and AFLP analysis. African Journal of Biotechnology, 3(1), 25-31.

Bentley, S., Pegg, K.G., \& Dale, J.L. (1994). Optimization of RAPD-fingerprinting to analyze genetic variation within populations of Fusarium oxysporum f. sp. cubense. Journal of Phytopathology, 142, 64-78.

Bogale, M., Wingfield, B.D., Wingfield, M.J., \& Steenkamp, T. (2005). Simple sequence repeat for species in Fusarium oxysporum complex. Molecular Ecology Notes, 5, 622624.

Bogale, M., Wingfield, B.D., Wingfield, M.J., \& Steenkamp, E.T. (2006). Characterization of Fusarium oxysporum isolates from Ethiopia using AFLP, SSR and DNA sequence analyses. Fungal Diversity, 51-66.

Chen, W., Basandrai, A.K., Basandrai, D., Banniza, S., Bayaa, B., Buchwaldt, L., Davidson, J., Larsen, R., Rubiales, D., \& Taylor, P. (2009). Lentil Diseases and Their Management. In W. Erskine et al. (Eds.), The Lentil: Botany, Production and Uses (pp. 262-281). UK: CABI.

Datta, S., Choudhary, R.G., Shamim, Md., Singh, R.K., \& Dhar, V. (2011). Molecular diversity in Indian isolates of Fusarium oxysporum f.sp. lentis inciting wilt disease in lentil (Lens culinaris Medik). African Journal of Biotechnology 10(38), 7314-7323.

Earl Dent, A., \& von Holdt, B.M. (2012). STRUCTURE HARVESTER: a website and program for visualizing STRUCTURE output and implementing the Evanno method. Conservation Genetics Resources, 4(2), 359-361.

Erskine, W., \& Bayaa, B. (1996). Yield loss, incidence and inoculum density associated with vascular wilt of lentil. Phytopathologia Mediterranea, 36, 24-32.

Evanno, G., Regnaut, S., \& Goudet, J. (2005). Detecting the number of clusters of individuals using the software STRUCTURE: a simulation study. Molecular Ecology, 14, 26112620 .

Excoffier, L., Smouse, P.E., \& Quattro, J.M. (1992). Analysis of molecular variance inferred from metric distances among DNA haplotypes: application to human mitocondreal DNA restriction sites. Genetics, 131, 479-491. 
Excoffier, L., Laval, G., \& Schneider, S. (2005). Arlequin ver. 3.0: An integrated software package for population genetics data analysis. Evolutionary Bioinformatics Online, 1, 47-50.

Felsenstein, J. (1985). Confidence limits on phylogenies: an approach using the bootstrap. Evolution, 39, 783-791. doi: 10.2307/2408678.

Felsenstein, J. (2004). PHYLIP (Phylogeny Inference Package) Version 3.6. Department of Genomic Sciences, University of Washington, Seattle, WA.

Grajal-Martin, M.J., Simon, C.J., \& Muehlbauer, F.J. (1993). Use of random amplified polymorphic DNA (RAPD) to characterize race 2 of Fusarium oxysporum f. sp. pisi. Phytopathology, 83, 612-614.

Kalinowski, S.T. (2004). Counting alleles with rarefaction: private alleles and hierarchical sampling designs. Conservation Genetics, 5, 539-543.

Kalinowski, S.T. (2005). HP-Rare: a computer program for performing rarefaction on measures of allelic diversity. Molecular Ecology Notes, 5, 187-189.

Khare, M.N. (1981). Diseases of lentil. In C. Webb \& G. Hawtin ( Eds.), Lentil (pp.163-172). UK: CABI.

Kopelman, N.M., Mayzel, J., Jakobsson, M., Rosenberg, N.A., \& Mayrose, I. (2015). Clumpak: a program for identifying clustering modes and packaging population structure inferences across K. Molecular Ecology Resources 15, 1179-1191.

Kraft, J.M., Haware, M.P., Halila, H., \& Bayaa, B. (2000). Soilborne diseases and their control. In R. Knight (Ed.), Linking Research and Marketing Opportunities for Pulses in $21^{\text {st }}$ Century (pp.457-466). The Netherlands: Kluwer Academic.

Ma, L.J., van der Does, H.C., Borkovich, K.A. et al. (2010). Comparative genomics reveals mobile pathogenicity chromosomes in Fusarium. Nature, 464, 367-73.

Manulis, S., Kogan, N., Reuven, M., Ben-Yephet, Y. (1994). Use of the RAPD technique for identification of Fusarium oxysporum f. sp. dianthi from carnation. Phytopathology, $84,98-101$.

McDonald, B.A., \& Linde, C. (2002). The population genetics of plant pathogens and breeding strategies for durable resistance. Euphytica, 124, 163-180.

Mohammadi, N., Goltapeh, E.M., Babaie-Ahari, A., \& Pouralibaba, H. (2012). Pathogenic and genetic characterization of Iranian isolates of Fusarium oxysporum f. sp. lentis by ISSR analysis. Journal of Agricultural Technology, 7(1), 63-72.

Nelson, P. E., Toussoun, T. A., \& Marasas, W. F. O. (1983). Fusarium species: An Illustrated Manual for Identification. USA: The Pennsylvania State University Press. 
Nourollahi, K., \& Madahjalali, M . (2017). Analysis of population genetic structure of Iranian Fusarium oxysporum f. sp. lentis isolates using microsatellite markers. Australasian Plant Pathology, 46, 35-42.

O’Donnell, K., Cigelnik, E., \& Nirenberg, H.I. (1998). Molecular systematic and14 phylogeography of the Gibberella fujikuroi species complex. Mycologia, 90, 465-493.

Rousset, F. (2008). GENEPOP'007: A complete reimplementation of the GENEPOP software for Windows and Linux. Molecular Ecology Resources, 8, 103-106.

Pouralibaba, H.R., Rubiales, D., \& Fondevilla, S. (2016). Identification of pathotypes in Fusarium oxysporum f.sp. lentis. European Journal of Plant Pathology, 144, 539-549.

Pritchard, J.K., Stephens, M., \& Donnelly, P. (2000). Inference of population structure using multilocus genotype data. Genetics, 155, $945-959$.

SAS Institute( 2004). SAS/STAT® 9.1 User's Guide. SAS Institute Inc., Cary, NC.

Saghai Maroof, M.A., Zhang, Q., \& Biyashev, R. (1995). Comparison of restriction fragment length polymorphisms in wild and cultivated barley. Genome, 38, 298-306.

Taheri, N., Rastegar Fallahati, R., Jafarpour, B., Bagheri, A.R., \& Jahanbakhsh, V. (2010). Pathogenic and genetic characterization of Fusarium oxysporum f.sp. lentis by RAPD and IGS analysis in Khorasan province. World Applied Sciences Journal, 9 (3), 239244.

Torres, A.M., Weeden, N.F., \& Martín, A .(1993) Linkage among isozyme, RFLP and RAPD markers in Vicia faba. Theoretical and Applied Genetics, 85, 937-945.

Vigouroux, Y., Glaubitz, J.C., Matsuoka, Y., Goodman, M.M., Jesus, S.G., \& Doebley, J. (2008). Population structure and genetic diversity of new world maize races assessed by DNA microsatellites. American Journal of Botany, 95, 1240-1253.

Vogelgsang, S., Enkerli, J., Jenny, E., Roffler, S., \& Widmer, F. (2011). Characterization of Fusarium poae Microsatellite Markers on Strains from Switzerland and Other Countries. Journal of Phytopathology, 159, 197-200.

You, F.M., Huo, N.X., Gu, Y.Q., Luo, M.C., Ma, Y.Q., Hane, D., Lazo, G.R., Dvorak, J. \& Anderson, O.D. (2008). BatchPrimer3: a high throughput web application for PCR and sequencing primer design. BMC Bioinfomatics, 9, 253. 
Figure caption:

Fig. 1: The choice of the most likely number of clusters $(\mathrm{K})$ inferred from six microsatellite markers of 47 Fusarium oxysporum f. sp. lentis (FOL) and a F. oxysporum f. sp. pisi (FOP) isolates using a model-based clustering method of Pritchard et al. (2000): $\ln P(X \mid \mathrm{K})$ values for each of the 30 independent runs for each $\mathrm{K}$ and $\Delta K$ values for each $\mathrm{K}$ based on the second order rate of change of the likelihood function with respect to $\mathrm{K}$ described by Evanno et al. (2005).

Fig. 2: Fitch-Margoliash tree of 47 Fusarium oxysporum f. sp. lentis (FOL) isolates and the proportion of membership in each cluster at $\mathrm{K}=2$ and 7 as defined with a model-based clustering method from Pritchard et al. (2000) based on six microsatellite markers. Region of origin of each sample is indicated as follows: R1 Algeria, R2 Syria, R3 NW Iran, R4 NE Iran. The pathotypes are shown in brackets (P1-P7). The FM tree was rooted using F. oxysporum $\mathrm{f}$. sp. pisi (FOP) isolate as an outgroup. Bootstrap support values $>50 \%$ of 1,000 replicates are given above branches. Each individual isolate is represented by a single horizontal line divided into colours. Each colour represents one cluster, and the length of the coloured segment shows the individual's estimated proportion of membership in that cluster. Cluster membership of each isolate is indicated on the left (at $K=2$ ) and on the right (at $K=7$ ) of the diagram. 
1 Table 1 Code, origin and pathotype of the F. oxysporum f. sp. lentis (FOL) and the F. oxysporum $\mathrm{f}$. sp.

2 pisi (FOP) isolates used in the studies

\begin{tabular}{|c|c|c|c|c|}
\hline $\begin{array}{c}\text { Isolate } \\
\text { code }\end{array}$ & $\begin{array}{c}\text { Isolate } \\
\text { number in } \\
\text { Pouralibaba } \\
\text { et al. } 2016 \\
\end{array}$ & Region & Province, location/village & Pathotype $^{b}$ \\
\hline $\mathrm{S} 02$ & 54 & Algeria & Mascara,Site 1 & 4 \\
\hline S03 & 56 & Algeria & Sidi Bel-Abbas, Site 1 & 7 \\
\hline S04 & 57 & Algeria & Sidi Bel-Abbas, Site 2 & 7 \\
\hline S06 & 41 & Syria & Aleppo,ICARDA & 3 \\
\hline S07 & 42 & Syria & Aleppo,ICARDA & 1 \\
\hline S08 & 43 & Syria & Aleppo,Eshraf & 6 \\
\hline S09 & 44 & Syria & Hama, Al-Eskandaryeh & 3 \\
\hline $\mathrm{S} 10$ & 45 & Syria & Idlib,Maharez & 7 \\
\hline S15 & 5 & NW Iran & Bukan & 2 \\
\hline S16 & 6 & NW Iran & Naghadeh, Km $5^{\text {th }}$ Naqadeh - Piranshahr & 3 \\
\hline S17 & 7 & NW Iran & Oshnavyeh, Km $8^{\text {th }}$ Oshnavyeh - Orumiyeh & 1 \\
\hline $\mathrm{S} 18$ & 8 & NW Iran & Miyandoab, Km $20^{\text {th }}$ Miyandoab - Mahabad & 7 \\
\hline S19 & 10 & NW Iran & Varzeghan, km $10^{\text {th }}$ Varzeghan - Kharvana & 7 \\
\hline $\mathrm{S} 20$ & 12 & NW Iran & Moghan, Ghare-Ghasemlu & 7 \\
\hline $\mathrm{S} 21$ & 13 & NW Iran & Moghan, Zargaran & 7 \\
\hline $\mathrm{S} 22$ & 14 & NW Iran & Moghan,Gog-Tapeh & 5 \\
\hline $\mathrm{S} 23$ & 15 & NW Iran & Moghan, Ruh-Kandi & 2 \\
\hline $\mathrm{S} 24$ & 17 & NW Iran & Varzeghan & 7 \\
\hline $\mathrm{S} 25$ & 19 & NW Iran & Moghan,Damirchi & 2 \\
\hline S32 & 34 & NW Iran & Moghan, Gog-Tapeh & 2 \\
\hline S33 & 35 & NW Iran & Moghan,Gog-Tapeh & 7 \\
\hline S34 & 36 & NW Iran & Moghan,Gog-Tapeh & 1 \\
\hline S35 & 2 & NE Iran & Mash'had, Pardis & 3 \\
\hline S36 & 9 & NE Iran & Mash'had, Pardis & 5 \\
\hline S37 & 11 & NE Iran & Bojnourd & 7 \\
\hline S38 & 16 & NE Iran & Maneh-Samlaghan & 3 \\
\hline S39 & 18 & NE Iran & Maneh-Samlaghan & 7 \\
\hline $\mathrm{S} 40$ & 21 & NE Iran & Mash'had, Pardis & 7 \\
\hline S41 & 23 & NE Iran & Bardaskan & 3 \\
\hline $\mathrm{S} 42$ & 29 & NE Iran & Bardaskan & 7 \\
\hline $\mathrm{S} 43$ & 30 & NE Iran & Bojnourd & 2 \\
\hline S44 & 31 & NE Iran & Maneh-Samlaghan & 3 \\
\hline S45 & 33 & NE Iran & Maneh-Samlaghan & 2 \\
\hline $\mathrm{S} 46$ & 38 & NE Iran & Maneh-Samlaghan & 2 \\
\hline S47 & 39 & NE Iran & Mash'had, Pardis & 2 \\
\hline FOP & & USA & Pullman & \\
\hline
\end{tabular}

$3 \quad{ }^{\mathrm{a}} \mathrm{NE}$ and NW $=$ North East and North West, respectively.

$4 \quad$ b According to Pouralibaba et al. 2016. 
Table 2 Primer sequences, SSR motif, amplification conditions, amplicon size range, diversity traits and putative chromosome location of SSRs analysed in the collection of 47 F. oxysporum f.sp. lentis isolates

\begin{tabular}{|c|c|c|c|c|c|c|c|c|c|}
\hline No. & Marker $^{\mathrm{a}}$ & Primers sequences (3'-5') & SSR motif & $\begin{array}{l}\text { Annealing } \\
\text { Temp. }\left({ }^{\circ} \mathbf{C}\right)\end{array}$ & $\underset{(\mathrm{mM})}{\mathrm{MgCl}_{2}}$ & $\begin{array}{l}\text { Amplicon size } \\
\text { range (bp) }\end{array}$ & $\begin{array}{l}\text { No of } \\
\text { alleles }\end{array}$ & $\boldsymbol{H}_{\boldsymbol{E}}^{\mathrm{b}}$ & $\begin{array}{l}\text { Chromosome position } \\
(\text { Chr.: bp })^{\text {c }}\end{array}$ \\
\hline 1 & MB14* & $\begin{array}{l}\text { Fw:CGTCTCTGAACCACCTTCATC } \\
\text { Rv: TTCCTCCGTCCATCCTGAC }\end{array}$ & $(\mathrm{CCA})_{5}$ & 57 & 2.5 & $201-213$ & 2 & 0.322 & Chr. 1: 3,925,915 \\
\hline 2 & MB11* & $\begin{array}{l}\text { Fw: GTGGACGAACACCTGCATC } \\
\text { Rv: AGATCCTCCACCTCCACCTC }\end{array}$ & $(\mathrm{GGC})_{7}$ & 68 & 2.5 & $190-200$ & 4 & 0.707 & Chr. 4: 1,635,005 \\
\hline 3 & MB18 & $\begin{array}{l}\text { Fw: GTAGGAAATGACGAAGCTGAC Rv: } \\
\text { TGAGCACTCTAGCACTCCAAAC }\end{array}$ & $(\mathrm{CAACA})_{6}$ & 57 & 2.5 & $286-310$ & 5 & 0.784 & Chr. 4: 3,657,593 \\
\hline 4 & SSR17 & $\begin{array}{l}\text { Fw: AGGATTTGGTTTCTTGTTCTC } \\
\text { Rv: ACCTCATGATCTATCCTGTCC }\end{array}$ & $(\mathrm{AGT})_{4}$ & 50 & 2.5 & $169-179$ & 4 & 0.603 & Chr. 5: 3,446,927 \\
\hline 5 & SSR18 & $\begin{array}{l}\text { Fw: GAAGGTAAGGTTTGGTGAAGT } \\
\text { Rv: GTAGGCCGTACCTACCTAGC }\end{array}$ & $(\mathrm{CCTGG})_{3}$ & 50 & 1.5 & $142-194$ & 6 & 0.748 & Chr. 5: 3,453,750 \\
\hline 6 & SSR8* & $\begin{array}{l}\text { Fw: TCATATTATTGGGCTGAGAGA } \\
\text { Rv: AGGCTCTGAAGCTGTTTTATT }\end{array}$ & $(\mathrm{AC})_{6}$ & 50 & 2.5 & $144-157$ & 7 & 0.714 & Chr. 5: 4,413,845 \\
\hline 7 & SSR6 & $\begin{array}{l}\text { Fw: CAGGCTTCAGTCCCTAATATC } \\
\text { RV: CATGATGAAAATATACGAGAA }\end{array}$ & $(\mathrm{TCACT})_{3}$ & 50 & 2.5 & $158-165$ & 4 & 0.679 & Chr. 5: 4,446,929 \\
\hline 8 & SSR14 & $\begin{array}{l}\text { Fw: GATCGTTAGGAGAGCTAAAGG } \\
\text { Rv: CAATCTAGGCATTCTCTTTCA }\end{array}$ & $(\mathrm{CA})_{6}$ & 50 & 1.5 & $166-168$ & 2 & 0.313 & Chr. 7: 2,310,847 \\
\hline 9 & SSR15* & $\begin{array}{l}\text { Fw: GCAGGTGTCTGTCACTTGTAT } \\
\text { Rv: CGTTGATGTAGAGAACAAAGG }\end{array}$ & $(\mathrm{TCG})_{6}$ & 50 & 2.5 & $161-187$ & 7 & 0.818 & Chr. 7: 2,318,036 \\
\hline 10 & SSR21 & $\begin{array}{l}\text { Fw: TCTCCAATAACATCATCCTCA } \\
\text { Rv: GAGGATAGCGAAGAGAAGAAG }\end{array}$ & $(\mathrm{TCC})_{6}$ & 55 & 2.5 & $149-161$ & 4 & 0.638 & Chr. 8: 1,806,301 \\
\hline 11 & SSR23* & $\begin{array}{l}\text { Fw: GATGATGATGTTTGGGAGAC } \\
\text { Rv: CGCGACACTTCATATAAAAAC }\end{array}$ & $(\text { CGTGAC })_{3}$ & 55 & 2.5 & $152-173$ & 5 & 0.688 & Chr. 8: 1,810,577 \\
\hline 12 & MB2* & $\begin{array}{l}\text { Fw: TGCTGTGTATGGATGGATGG } \\
\text { Rv: CATGGTCGATAGCTTGTCTCAG }\end{array}$ & $(\mathrm{GT})_{11}(\mathrm{GA})_{6}$ & 57 & 2.5 & $236-285$ & 10 & 0.867 & Chr. 9: 2,166,733 \\
\hline
\end{tabular}

${ }^{a}$ SSR markers are newly developed in the present study and MB markers are those reported by Bogale et al. 2015

${ }^{\mathrm{b}}$ Expected heterozygosity

${ }^{c}$ Obtained by blasting (BLASTN) the sequence amplified by the primers against the genome sequence of Fusarium oxysporum f. sp. lycopersici 4287 (Sequence ID:

NC_030994.1)

*SSR selected for analyses concerning genetic relationships and population structure 
Table 3: Significance level of linkage disequilibrium (LD) between all pairs of loci located on same chromosome in the $F$. oxysporum f.sp. lentis isolates from North-West Iran.

\begin{tabular}{cccc}
\hline Chromosome & Locus1 & Locus2 & $P^{\mathrm{a}}$ \\
\hline Chr. 4 & MB11 & MB18 & 0.004 \\
Chr. 5 & SSR6 & SSR8 & 0.051 \\
Chr. 5 & SSR6 & SSR17 & 0.002 \\
Chr. 5 & SSR6 & SSR18 & 0.000 \\
Chr. 5 & SSR8 & SSR17 & 0.314 \\
Chr. 5 & SSR8 & SSR18 & 0.066 \\
Chr. 5 & SSR17 & SSR18 & 0.000 \\
Chr. 7 & SSR14 & SSR15 & 0.017 \\
Chr. 8 & SSR21 & SSR23 & 0.000 \\
\hline
\end{tabular}

${ }^{\mathrm{a} S i g n i f i c a n c e ~ l e v e l s ~ a f t e r ~ s e q u e n t i a l ~ B o n f e r r o n i ~ a d j u s t m e n t s ~}$ 
Table 4 Sample size $(\mathrm{n})$, average number of alleles $\left(N_{a}\right)$, allelic richness $\left(N_{a r}\right)$, number of private alleles $\left(N_{p r}\right)$, private allelic richness $\left(N_{p a r}\right)$ and unbiased expected heterozygosity $\left(H_{E}\right)$ of 47 Fusarium oxysporum f. sp. lentis isolates for different regions based on 12 microsatellite loci

\begin{tabular}{|c|c|c|c|c|c|c|}
\hline Region & $\mathbf{n}$ & $N_{a}$ & $N_{a r}$ & $N_{p r}$ & $N_{p a r}$ & $\boldsymbol{H}_{\boldsymbol{E}}$ \\
\hline Algeria & 4 & 1.833 & 1.361 & 0 & 0.321 & 0.431 \\
\hline Syria & 8 & 2.833 & 1.567 & 0 & 0.597 & 0.618 \\
\hline $\mathrm{NW}^{\mathrm{a}} \operatorname{Iran}$ & 22 & 4.750 & 1.662 & 8 & 0.404 & 0.679 \\
\hline NE Iran & 13 & 3.000 & 1.427 & 3 & 0.356 & 0.445 \\
\hline
\end{tabular}

${ }^{\mathrm{a}} \mathrm{NE}$ and NW $=$ North East and North West, respectively 
Table 5 Analysis of molecular variance (AMOVA) for the partitioning of genetic diversity of Fusarium oxysporum f. sp. lentis (FOL) isolates based on six microsatellite loci (A) among and within regions (Algeria, Syria, NW Iran, NE Iran, and (B) between groups of regions (Iranian vs. non-Iranian), between regions within groups and within regions.

\begin{tabular}{clccccc}
\hline Analysis & Source of variation & $\mathbf{d f}$ & $\begin{array}{c}\text { Variance } \\
\text { components }\end{array}$ & $\begin{array}{c}\text { \% Total } \\
\text { variance }\end{array}$ & $\phi$-statistics & $\boldsymbol{P}(\phi)^{\mathbf{a}}$ \\
\hline (A) $\quad$ Among regions & 3 & 0.21 & 13.45 & 0.134 & 0.0002 \\
& Within regions & 43 & 1.32 & 86.55 & & \\
(B) & $\begin{array}{l}\text { Between regions } \\
\text { within groups }\end{array}$ & 2 & 0.11 & 7.07 & 0.079 & 0.0268 \\
& $\begin{array}{l}\text { Wetween groups } \\
\text { Within regions }\end{array}$ & 1 & 0.16 & 10.17 & 0.102 & $<0.0001$ \\
\hline
\end{tabular}

${ }^{\mathrm{a}} \boldsymbol{\phi}$-statistic probability level after 10,000 permutations 
Table 6 AMOVA's pairwise $\phi_{S T}$ values and their significance between regions

\begin{tabular}{lccc}
\hline Region & Syria & NW Iran & NE Iran \\
\hline Argelia & $0.211^{\text {ns }}$ & $0.166^{*}$ & $0.426^{* *}$ \\
Syria & & $0.086^{*}$ & $0.277^{* * *}$ \\
NW Iran & & $0.048^{\text {ns }}$ \\
\hline -value significance levels: ${ }^{* * *} P<0.001 ;{ }^{* *} 0.001<P<0.01,{ }^{*} 0.01<P<0.05,{ }^{\text {ns }} P>0.05$
\end{tabular}



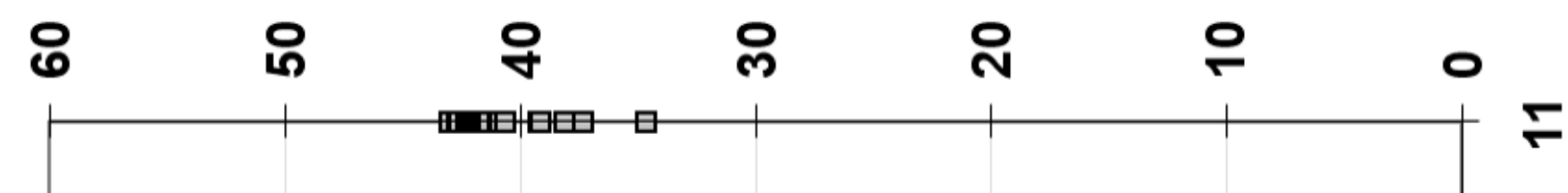

$\square$

미

III 口

口
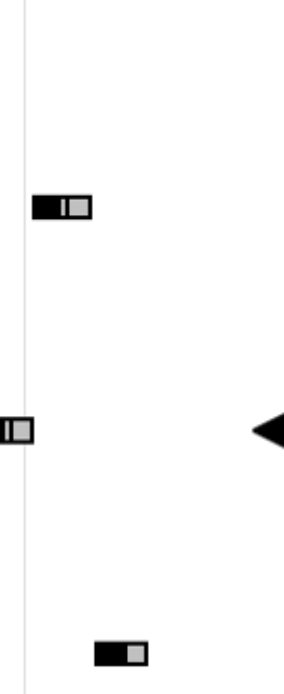

밈

IIIII)

\section{ํำ}

จั่

ஷั้

ণ্ণ

유ํ

ণ 
